\title{
Kinetics of Low-temperature CO Oxidation on $\mathrm{Au}(111)$
}

\author{
by \\ Theodore Thuening ${ }^{1}$, Joshua Walker ${ }^{1}$, Heather Adams ${ }^{1}$, Octavio Furlong ${ }^{2}$ and \\ Wilfred T. Tysoe * \\ ${ }^{1}$ Department of Chemistry and Biochemistry and Laboratory for Surface Studies, University of \\ Wisconsin-Milwaukee, Milwaukee, WI 53211, USA \\ ${ }^{2}$ Department of Physics Laboratorio de Ciencias de Superficies y Medios Porosos, Universidad \\ Nacional de San Luis, Chacabuco 917,5700 San Luis, Argentina
}

December 19, 2015

\begin{abstract}
The oxidation of carbon monoxide on oxygen-modified $\mathrm{Au}(111)$ surfaces is studied using a combination of reflection-absorption infrared spectroscopy (RAIRS) and temperatureprogrammed desorption (TPD). TPD reveals that $\mathrm{CO}$ desorbs in two states with the lowtemperature state have a peak temperature between 130 to $150 \mathrm{~K}$, and the higher-temperature state having a peak temperature that varies from $\sim 175$ to $220 \mathrm{~K}$ depending on the initial oxygen and $\mathrm{CO}$ coverages. Infrared spectroscopy indicates that the low-temperature CO desorption state is predominantly associated with $\mathrm{CO}$ adsorbed on $\mathrm{Au}^{\delta+}$ sites, while the higher-temperature states are due to $\mathrm{CO}$ on $\mathrm{Au}^{0}$ sites. No additional vibrational features are detected indicating that $\mathrm{CO}$ reacts directly with adsorbed atomic oxygen on gold to form $\mathrm{CO}_{2}$. Estimates of the activation energy for $\mathrm{CO}_{2}$ formation suggest that they are in the same range and found for supported gold catalysts at reaction temperature below $\sim 300 \mathrm{~K}$.
\end{abstract}

Paper submitted for publication in Somorjai Special Issue of Surface Science

Keywords: $\mathrm{Au}(111)$, oxygen, carbon monoxide, temperature-programmed desorption, reflectionabsorption infrared spectroscopy. 


\section{Introduction}

The Somorjai group pioneered the idea that the flexibility and restructuring of metal surfaces was crucial to its catalytic activity and proposed the notion that adsorption on the surface caused structural changes in the metal surface that caused it to become more active [1-6]. In particular, the gold surface has been found to undergo very significant adsorbate-induced structural changes [7-10]. Consequently, while bulk gold is a noble metal and considered to be unreactive, oxide-supported gold nanoparticles have been found to have quite remarkable catalytic activity for a number of reactions [11-14]. In particular, it forms the basis for active CO oxidation catalysts $[11,15-24]$. Water has been suggested to play a role in accelerating the rate of CO oxidation [24-27] and has been studied primarily using molecular beam methods on $\mathrm{Au}(111)[28,29]$. Previous work has also been carried to explore carbon monoxide oxidation on gold surfaces in the absence of water [30, 31].

It has been suggested that oxygen is activated by dissociating either directly on lowcoordination sites on the gold [32-34] or on the oxide support and the spilling over to the metal to then oxidize $\mathrm{CO}[34,35]$. In addition, it has been proposed that $\mathrm{CO}_{2}$ can form via an intermediate $\mathrm{Au}_{2} \mathrm{CO}_{3}{ }^{-}$carbonate complex rather than by a simple addition of adsorbed atomic oxygen to adsorbed carbon monoxide [36-38].

Since carbon monoxide adsorbs very weakly on low-Miller-index gold surfaces [39-42], but more strongly on step sites [39], reaction on $\mathrm{Au}(111)$ might not be expected to occur in temperature-programmed desorption (TPD) so that experiments have been performed primarily using molecular beams of carbon monoxide incident on a gold-covered surface [28, 29, 31]. However, as shown below, the adsorption of carbon monoxide on $\mathrm{Au}(111)$, in particular in the presence of co-adsorbed oxygen, is sufficiently strong that both TPD and reflection-absorption infrared spectroscopy (RAIRS) can be used to explore the reaction pathway. 
Controlled atomic oxygen coverages are obtained by exposing the surface to ozone [43], containing molecular oxygen, which does not adsorb at room temperature. TPD experiments show the direct oxidation of carbon monoxide on the gold surface, thereby allowing desorption and reaction activation energies to be estimated [44]. This also enables the surface to be interrogated using RAIRS over the same temperature range as that at which the oxidation chemistry occurs to search for any reaction intermediates such a carbonates since their vibrational frequencies [45] are distinct from those for $\mathrm{CO}$ on gold [46].

\section{Experimental Methods}

The apparatus used to collect RAIRS and TPD data has been described in detail elsewhere [47]. Infrared spectra were collected using a Bruker Equinox spectrometer, typically for 1000 scans at a resolution of $4 \mathrm{~cm}^{-1}$. TPD data were collected using a Dichor quadrupole mass spectrometer interfaced to a computer that allowed up to five masses to be monitored sequentially in a single experiment. The sample could be cooled to $80 \mathrm{~K}$ by thermal contact to a liquid-nitrogen-filled reservoir and resistively heated to $\sim 1200 \mathrm{~K}$.

A $\mathrm{Au}(111)$ single crystal (Princeton Scientific) was cleaned with cycles of ion bombardment using $1 \mathrm{keV}$ argon ions for 30 minutes $\left(1 \mu \mathrm{A} / \mathrm{cm}^{2}\right)$, annealing to $900 \mathrm{~K}$ for 5 minutes and then to $600 \mathrm{~K}$ for 30 minutes. Ozone was produced by an A2Z Ozone Inc., 5GLAB ozone generator where the output of the generator was connected via a Teflon tube directly to a high-precision variable leak valve through a $1 \mathrm{~mm}$-diameter glass tube that was directed at the inlet of the leak valve to minimize ozone decomposition. The ozone was returned through an external concentric glass tube and led though a Teflon tube to a fume hood. The proportion of ozone in the gas mixture was maximized by monitoring the $32\left(\mathrm{O}_{2}{ }^{+}\right)$and $48\left(\mathrm{O}_{3}{ }^{+}\right)$signals in the 
mass spectrometer located inside the vacuum chamber and it is estimated that the ozone concentration in the gas mixture is $\sim 4 \%$.

\section{Results and Discussion}

Oxygen Adsorption from Ozone on Au(111)

TPD data were collected for atomic oxygen adsorbed from ozone on $\mathrm{Au}(111)$ as a function of exposure. Oxygen (32 amu) desorbs in a sharp peak centered at $\sim 540 \mathrm{~K}$ at low coverages and shifts to higher coverages with exposure so that at the highest coverage desorbs at $\sim 560 \mathrm{~K}$ (data not shown). These desorption profiles and peak temperatures are in good agreement with previous measurements on $\mathrm{Au}(111)$ [43]. Measuring the oxygen coverage from the integrated area under the desorption peak compared with previous results allows the oxygen coverage to be calibrated as a function of exposure to the mixture of $\mathrm{O}_{2}+\mathrm{O}_{3}$, and the results described below use oxygen coverages calibrated in this way.

\section{Carbon Monoxide Oxidation on Au(111)}

The oxidation of $\mathrm{CO}$ was explored using TPD on oxygen-covered $\mathrm{Au}(111)$ by adsorbing atomic oxygen using ozone [43]. A series of TPD spectra for a Au(111) sample initially containing 0.2 ML of atomic oxygen are shown in Figure 1 as a function of $\mathrm{CO}$ exposure. $\mathrm{CO}$ (28 amu) is found to desorb in two distinct states from oxygen-covered $\mathrm{Au}(111)$ at $~ 132$ and 174

$\mathrm{K}$ (Figure 1A), that grow approximately equally as a function of $\mathrm{CO}$ exposure. This results in low-temperature $\mathrm{CO}_{2}$ (44 amu) formation (Figure 2B), initially in a single peak centered at $\sim 168$ $\mathrm{K}$ that grows with increasing $\mathrm{CO}$ exposure, followed by the growth of an additional $\mathrm{CO}_{2}$ state at $\sim 142 \mathrm{~K}$. Clearly, the high-temperature $\mathrm{CO}_{2}$ state must be associated with oxidation of the more stable $\mathrm{CO}$ that desorbs at $\sim 174 \mathrm{~K}$ (Figure 1A). The reaction of carbon monoxide with surface atomic oxygen is confirmed by the decrease in intensity of the remaining oxygen (32 amu) 
feature with increasing $\mathrm{CO}$ exposure (Figure 2C).

The corresponding results for a higher oxygen coverage of $0.75 \mathrm{ML}$ are shown in Figure 2. Now the lower-temperature $\mathrm{CO}$ desorption state $(28 \mathrm{amu})$, centered at $\sim 153 \mathrm{~K}$, is less intense than the higher-temperature CO desorption state that shifts in temperature from $\sim 190$ to $222 \mathrm{~K}$ (Figure 2A). Intense $\mathrm{CO}_{2}$ desorption states (44 amu) are measured with a peak initially appearing at $\sim 173 \mathrm{~K}$, shifting to higher temperatures up to $\sim 212 \mathrm{~K}$ as the $\mathrm{CO}$ exposure increases (Figure 2B).

The effect of varying the oxygen coverage is shown in Figure 3 for a $\mathrm{CO}$ exposure of 10 $\mathrm{L}$, resulting in saturation of the surface with $\mathrm{CO}$. Again, two $\mathrm{CO}(28 \mathrm{amu})$ desorption states are observed; a low-temperature state centered at $\sim 141 \mathrm{~K}$ that initially grows in parallel with the higher-temperature state, and then decreases in intensity for oxygen coverages above $\sim 0.9 \mathrm{ML}$, while both states decrease in intensity at higher oxygen coverages (Figure 3A). Carbon dioxide (44 amu) desorbs in a broad feature between $~ 130$ and $210 \mathrm{~K}$, with an intensity that grows up to an oxygen coverage of $\sim 0.9 \mathrm{ML}$, and then decreases (Figure 3B). The corresponding oxygen desorption profiles (32 amu) are shown in Figure 3C, which are identical in shape to those found on clean $\mathrm{Au}(111)$ [43]. The resulting stoichiometric reaction between adsorbed $\mathrm{CO}$ and oxygen is illustrated by the data in Figure 4. This plots the coverage of $\mathrm{CO}_{2}$ that is produced (•) and the adsorbed oxygen that is consumed ( $\boldsymbol{\square})$ as a function of oxygen coverage. Here the coverage of oxygen consumed is measured from the area of the 32 amu profile in the presence of carbon monoxide (Figure 3C) compared to the area for an identical oxygen dose without CO. There is good agreement between the two sets of data indicating a quantitative reaction between adsorbed oxygen and $\mathrm{CO}$ (Figure 4). The carbon dioxide that is initially formed is limited by the inventory of oxygen on the surface, which is completely consumed by reaction with CO. At higher oxygen coverages, some oxygen remains on the surface so that the $\mathrm{CO}_{2}$ yield becomes 
limited by the amount of carbon monoxide. However, in this case, not all of the carbon monoxide is consumed and a portion desorbs when there is still oxygen on the surface. At coverages above $\sim 0.8 \mathrm{ML}$ of oxygen, the carbon dioxide yield decreases due to the blocking of $\mathrm{CO}$ adsorption by atomic oxygen.

The corresponding infrared spectra for $\mathrm{CO}$ on clean $\mathrm{Au}(111)$ following adsorption at 87 $\mathrm{K}$ are shown in Figure 5A. The spectrum at $87 \mathrm{~K}$ exhibits a peak at $2110 \mathrm{~cm}^{-1}$, close to the value of $2118 \mathrm{~cm}^{-1}$ found previously for low-temperature $\mathrm{CO}$ adsorption on $\mathrm{Au}(111)$ [48]. Additional spectra show the effect of heating the surface to various temperatures for $10 \mathrm{~s}$ and then allowing the sample to cool once again to $\sim 87 \mathrm{~K}$ following which the spectrum was collected. This shows a decrease in the intensity of the infrared peaks and the inset plots the integrated absorbance of the infrared features as a function of annealing temperature. An additional shift in peak position is noted as the $\mathrm{CO}$ coverage changes due to a combination of dipolar coupling and chemical shifts $[49,50]$. The CO vibrational frequency of $2110 \mathrm{~cm}^{-1}$ is in good agreement with results for high pressures of $\mathrm{CO}$ on $\mathrm{Au}(110)$ [51] and for $\mathrm{CO}$ adsorption at low-temperatures on $\mathrm{Au}(211)$ [39] and $\mathrm{Au}(332)$ surfaces [42]. However, $\mathrm{CO}$ adsorption on $\mathrm{Au}(111)$ at high pressures (up to 100 Torr) showed a single infrared mode at $2060 \mathrm{~cm}^{-1}$ that did not change position with coverage [41]. In this case, considerable surface restructuring was noted at those higher $\mathrm{CO}$ pressures [52]. It has been shown that the $\mathrm{CO}$ stretching frequency, while being relatively insensitive to gold coordination number, is a reasonably sensitive probe of the gold charge state [46], where $\mathrm{Au}^{0}-\mathrm{CO}$ has a CO stretching mode between 2130 and $2090 \mathrm{~cm}^{-}$ ${ }^{1}$ in agreement with a frequency of $\sim 2110 \mathrm{~cm}^{-1}$ found in Figure 5A.

Figure 5B shows the $\mathrm{CO}$ stretching region of $\mathrm{CO}$ adsorbed on a surface containing 0.2 ML of oxygen as a function of CO exposure. Two infrared peaks at 2135 and $2110 \mathrm{~cm}^{-1}$ grow simultaneously with increasing $\mathrm{CO}$ exposure, corresponding to the growth of two desorption 
states found in TPD (Figure 1). Comparison with the infrared spectrum on clean $\mathrm{Au}(111)$ (Figure 5A) suggests that the $2135 \mathrm{~cm}^{-1}$ state is induced by co-adsorbed atomic oxygen while the $2110 \mathrm{~cm}^{-1}$ state is due to $\mathrm{CO}$ on unaffected sites. The appearance of the feature at $\sim 2135 \mathrm{~cm}^{-1}$ is consistent with $\mathrm{CO}$ adsorption on $\mathrm{Au}^{\delta+}$ sites [46], which appear at higher frequencies than $\mathrm{CO}$ on $\mathrm{Au}^{0}$ sites, generally between 2150 and $2190 \mathrm{~cm}^{-1}$.

The evolution in the infrared spectra as a function of annealing temperature is shown in Figure $5 \mathrm{C}$ for a saturation $\mathrm{CO}$ exposure of $\sim 10 \mathrm{~L}$. The results were obtained by heating to the indicated temperature and then allowing the sample to cool once again, following which the infrared spectra were collected. The higher $\mathrm{CO}$ coverages in this case result in additional spectral shifts compared to the data with lower $\mathrm{CO}$ coverages (Figure 5B). In particular, the peak for $\mathrm{CO}$ on oxygen-modified sites shifts to $\sim 2141 \mathrm{~cm}^{-1}$. The variation in integrated peak area as a function of annealing temperature is shown plotted as an inset to Figure 5C where the peak desorption temperatures found for the same surface (Figure 1A), are indicated. This reveals that that the low-temperature $(\sim 132 \mathrm{~K})$ desorption feature in Figure 1 is associated with $\mathrm{CO}$ bound to $\mathrm{Au}^{\delta+}$ sites, while the higher temperature, $\sim 174 \mathrm{~K}$ state is due to $\mathrm{CO}$ adsorbed on $\mathrm{Au}^{0}$ sites.

No other vibrational modes were detected during this experiment indicating that $\mathrm{CO}$ reacts directly with adsorbed atomic oxygen to form carbon dioxide without forming any stable surface intermediates.

\section{Discussion}

Addition of oxygen to the surface produced two distinct $\mathrm{CO}$ desorption states comprising a low-temperature state with a peak centered between 130 to $150 \mathrm{~K}$, and a higher-temperature state with a peak temperature that varies from $\sim 175$ to $\sim 220 \mathrm{~K}$ depending on the initial oxygen 
and CO coverages. A Redhead analysis [44] using the experimental heating rate and assuming a pre-exponential factor of $1 \times 10^{13} \mathrm{~s}^{-1}$ yield $\mathrm{CO}$ desorption activation energies of 32 to $37 \mathrm{~kJ} / \mathrm{mol}$ for the low-temperature state and from 44 to $56 \mathrm{~kJ} / \mathrm{mol}$ for the high-temperature state. The infrared data suggest that the low-temperature states are associated with $\mathrm{CO}$ adsorbed on $\mathrm{Au}^{\delta+}$ sites and the higher-temperature desorption features are due to adsorption on gold sites.

The $\mathrm{CO} 4 \sigma, 1 \pi$ and $5 \sigma$ orbitals are located below the bottom of the gold d-band while the $2 \pi *$ orbitals located are close to the Fermi level [53] corresponding to the conventional Blyholder model for $\mathrm{CO}$ adsorption on transition-metal surfaces [54]. However, the low density of states of gold near the Fermi level leads to only relatively weak back donation into the $2 \pi *$ level, with $\mathrm{CO}$ acting as a weak $\pi$-acceptor, resulting in low binding energies. Thus removing electron density from the gold by co-adsorbing atomic oxygen increases the energy difference between the Fermi energy and the $\mathrm{CO} 2 \pi^{*}$ orbitals, thereby weakening the bonding as found experimentally. A similar shift to higher frequencies (in this case to $\sim 2146 \mathrm{~cm}^{-1}$ ) has been seen for $\mathrm{CO}$ co-adsorbed with hydroxyl species on $\mathrm{Au}(111)$ [48] consistent with this bonding model.

However, creating low-coordination sites on a roughened surface can increase the binding strength of $\mathrm{CO}$ [55]. In fact, the desorption peak temperatures for the two $\mathrm{CO}$ desorption states found on oxygen-modified $\mathrm{Au}(111)$ are very similar to those found for gold nanoparticles on $\mathrm{FeO}[56]$ and on surfaces roughened by oxygen or argon ion bombardment [57] indicating that surface roughening has some influence on $\mathrm{CO}$ binding. It is interesting to note that the infrared spectrum of $\mathrm{CO}$ adsorbed on gold nanoparticles on $\mathrm{FeO}$ exhibits a single vibrational feature centered at $\sim 2108 \mathrm{~cm}^{-1}$, similar to the low-frequency feature found on the oxygencovered surface (Figure 5B and 5C). However, the $\mathrm{CO}$ stretching frequency on gold is notoriously insensitive to surface structure, as evidenced by the similarity between the vibrational frequency on $\mathrm{Au}(111)$ (Figure 5A) and on oxygen-covered surfaces, which have been 
roughed by oxygen adsorption. Heating $\mathrm{CO}$-covered gold nanoparticles on FeO resulted in a reduction in the intensity of the $2108 \mathrm{~cm}^{-1}$ peak over a temperature range that was coincident the high-temperature ( $200 \mathrm{~K}) \mathrm{CO}$ desorption state, while no intensity decrease was noted when $\mathrm{CO}$ desorbed at lower temperatures. This was ascribed to the weakly bound CO that desorbs at $\sim 130$ $\mathrm{K}$, but which lies parallel to the surface, and is thus infrared forbidden $[56,58]$.

In the case of oxygen-modified $\mathrm{Au}(111)$, the $\sim 2141 \mathrm{~cm}^{-1}$ vibrational mode, assigned to $\mathrm{CO}$ adsorption on $\mathrm{Au}^{\delta+}$ sites, decreases in intensity coincident with the low-temperature $\mathrm{CO}$ desorption peak but does not exclude the possibility of there also being some infrared-invisible $\mathrm{CO}$ also being present on the surface.

Adsorbed $\mathrm{CO}$ reacts quantitatively with adsorbed atomic oxygen to form carbon dioxide (Figure 4) where the amount of carbon dioxide initially increases with oxygen coverage but decreases at higher coverages due to site blocking similar to the behavior found previously for $\mathrm{CO}$ oxidation on $\mathrm{Au}(111)$ using molecular beams of $\mathrm{CO}$ [31]. No intermediate surface species are detected following $\mathrm{CO}$ adsorption on oxygen-covered $\mathrm{Au}(111)$, indicating that $\mathrm{CO}_{2}$ is formed by a direct coupling between $\mathrm{CO}$ and adsorbed oxygen to immediately desorb $\mathrm{CO}_{2}[59]$. The carbon dioxide that is formed desorbs over the same range as $\mathrm{CO}$ suggesting that the activation energies for $\mathrm{CO}_{2}$ formation also lie approximately in the range of $\sim 32$ to $56 \mathrm{~kJ} / \mathrm{mol}$ and is in the same range as the activation energies for $\mathrm{CO}$ oxidation on gold nanoparticle catalysts for reaction carried out below $\sim 300 \mathrm{~K}[23]$. In particular, the $\mathrm{CO}_{2}$ formation temperatures in TPD are much lower than those found on main group transition metals where it forms between 300 and $500 \mathrm{~K}$ on $\mathrm{Rh}(111)$ [60], between 400 and $500 \mathrm{~K}$ om Ni(111) [61], from 200 to $500 \mathrm{~K}$ on $\mathrm{Pd}(111)$ [62] and at $\sim 350 \mathrm{~K}$ on $\mathrm{Pt}(111)$ [63].

\section{Conclusions}


Combined infrared and TPD experiments reveal that $\mathrm{Au}(111)$ single crystals exposed to ozone to form adsorbed atomic oxygen can oxidize $\mathrm{CO}$ to $\mathrm{CO}_{2}$ at temperatures as low as $\sim 140 \mathrm{~K}$. $\mathrm{CO}$ desorbs in two states where the low-temperature state is assigned to $\mathrm{CO}$ adsorbed on $\mathrm{Au}^{\delta+}$ sites and the higher-temperature desorption features are due to adsorption on gold sites. This observation is consistent with the Blyholder model. However, the low-temperature state may also include contributions from infrared-invisible $\mathrm{CO}$ bound with its axis parallel to the surface.

Carbon dioxide forms over the same temperature range as that at which $\mathrm{CO}$ desorbs suggesting that the formation activation energy is between $\sim 32$ to $56 \mathrm{~kJ} / \mathrm{mol}$, in the range for $\mathrm{CO}$

oxidation by supported catalysts. Infrared spectroscopy reveals only features due to molecularly adsorbed carbon monoxide suggesting that the $\mathrm{CO}_{2}$ forms directly without the intervention of any other intermediate species such as carbonates.

\section{Acknowledgements}

We gratefully acknowledge the support of this work by the National Science Foundation, under grant number CHE-1109377.

\section{References}

[1] R.J. Koestner, M.A. Van Hove, G.A. Somorjai, Molecular structure of hydrocarbon monolayers on metal surfaces, The Journal of Physical Chemistry, 87 (1983) 203-213. [2] G.A. Somorjai, The flexible surface. Correlation between reactivity and restructuring ability, Langmuir, 7 (1991) 3176-3182.

[3] G.A. Somorjai, The experimental evidence of the role of surface restructuring during catalytic reactions, Catal. Lett., 12 (1992) 17-34.

[4] G.A. Somorjai, Molecular concepts of heterogeneous catalysis, Journal of Molecular 
Structure: THEOCHEM, 424 (1998) 101-117.

[5] G.A. Somorjai, The Development of Molecular Surface Science and the Surface Science of Catalysis: The Berkeley Contribution, The Journal of Physical Chemistry B, 104 (2000) 29692979.

[6] G.A. Somorjai, The Evolution of Surface Chemistry. A Personal View of Building the Future on Past and Present Accomplishments, The Journal of Physical Chemistry B, 106 (2002) 92019213.

[7] J. Gong, Structure and Surface Chemistry of Gold-Based Model Catalysts, Chemical Reviews, 112 (2012) 2987-3054.

[8] P. Maksymovych, J.T. Yates, Au Adatoms in SelfAssembly of Benzenethiol on the Au(111) Surface, Journal of the American Chemical Society, 130 (2008) 7518-7519.

[9] J. Boscoboinik, J. Kestell, M. Garvey, M. Weinert, W. Tysoe, Creation of Low-Coordination Gold Sites on Au(111) Surface by 1,4-phenylene Diisocyanide Adsorption, Topics in Catalysis, $54(2011) 20-25$.

[10] J.A. Boscoboinik, F.C. Calaza, Z. Habeeb, D.W. Bennett, D.J. Stacchiola, M.A. Purino, W.T. Tysoe, One-dimensional supramolecular surface structures: 1,4-diisocyanobenzene on Au(111) surfaces, Phys. Chem. Chem. Phys., 12 (2010) 11624-11629.

[11] M. Haruta, N. Yamada, T. Kobayashi, S. Iijima, Gold catalysts prepared by coprecipitation for low-temperature oxidation of hydrogen and of carbon monoxide, Journal of Catalysis, 115 (1989) 301-309.

[12] M. Haruta, Size- and support-dependency in the catalysis of gold, Catal. Today, 36 (1997) 153-166.

[13] G. Hutchings, Catalysis: A golden future, Gold Bulletin, 29 (1996) 123-130. 
[14] J. Edwards, P. Landon, A.F. Carley, A.A. Herzing, M. Watanabe, C.J. Kiely, G.J.

Hutchings, Nanocrystalline gold and gold-palladium as effective catalysts for selective oxidation, Journal of Materials Research, 22 (2007) 831-837.

[15] A.A. Herzing, C.J. Kiely, A.F. Carley, P. Landon, G.J. Hutchings, Identification of Active Gold Nanoclusters on Iron Oxide Supports for CO Oxidation, Science, 321 (2008) 1331-1335. [16] A.M. Venezia, L.F. Liotta, G. Pantaleo, V. La Parola, G. Deganello, A. Beck, Z. Koppány, K. Frey, D. Horváth, L. Guczi, Activity of $\mathrm{SiO}_{2}$ supported gold-palladium catalysts in $\mathrm{CO}$ oxidation, Applied Catalysis A: General, 251 (2003) 359-368.

[17] L. Guczi, G. Petö, A. Beck, K. Frey, O. Geszti, G. Molnár, C. Daróczi, Gold Nanoparticles Deposited on $\mathrm{SiO}_{2} / \mathrm{Si}(100)$ : Correlation between Size, Electron Structure, and Activity in CO Oxidation, J. Am. Chem. Soc., 125 (2003) 4332-4337.

[18] C. Xu, J. Su, X. Xu, P. Liu, H. Zhao, F. Tian, Y. Ding, Low Temperature CO Oxidation over Unsupported Nanoporous Gold, J. Am. Chem. Soc., 129 (2007) 42-43.

[19] J.-D. Grunwaldt, C. Kiener, C. Wögerbauer, A. Baiker, Preparation of Supported Gold Catalysts for Low-Temperature CO Oxidation via "Size-Controlled" Gold Colloids, Journal of Catalysis, 181 (1999) 223-232.

[20] Y. Liu, C.-J. Jia, J. Yamasaki, O. Terasaki, F. Schüth, Highly Active Iron Oxide Supported Gold Catalysts for CO Oxidation: How Small Must the Gold Nanoparticles Be?, Angewandte Chemie International Edition, 49 (2010) 5771-5775.

[21] M. Comotti, W.-C. Li, B. Spliethoff, F. Schüth, Support Effect in High Activity Gold Catalysts for CO Oxidation, J. Am. Chem. Soc., 128 (2006) 917-924.

[22] M. Valden, S. Pak, X. Lai, D.W. Goodman, Structure sensitivity of CO oxidation over model $\mathrm{Au} / \mathrm{TiO}_{2}$ catalysts, Catal. Lett., 56 (1998) 7-10.

[23] M. Haruta, Nanoparticulate gold catalysts for low-temperature CO oxidation, Journal of 
New Materials for Electrochemical Systems, 7 (2004) 163-172.

[24] T. Fujitani, I. Nakamura, M. Haruta, Role of Water in CO Oxidation on Gold Catalysts, Catal. Lett., 144 (2014) 1475-1486.

[25] J. Saavedra, H.A. Doan, C.J. Pursell, L.C. Grabow, B.D. Chandler, The critical role of water at the gold-titania interface in catalytic CO oxidation, Science, 345 (2014) 1599-1602.

[26] M. Date, M. Haruta, Moisture effect on $\mathrm{CO}$ oxidation over $\mathrm{Au} / \mathrm{TiO}_{2}$ catalyst, Journal of Catalysis, 201 (2001) 221-224.

[27] M. Date, M. Okumura, S. Tsubota, M. Haruta, Vital role of moisture in the catalytic activity of supported gold nanoparticles, Angew. Chem.-Int. Edit., 43 (2004) 2129-2132.

[28] R.A. Ojifinni, N.S. Froemming, J. Gong, M. Pan, T.S. Kim, J.M. White, G. Henkelman, C.B. Mullins, Water-Enhanced Low-Temperature CO Oxidation and Isotope Effects on Atomic Oxygen-Covered Au(111), Journal of the American Chemical Society, 130 (2008) 6801-6812. [29] T.S. Kim, J. Gong, R.A. Ojifinni, J.M. White, C.B. Mullins, Water activated by atomic oxygen on $\mathrm{Au}(111)$ to oxidize CO at low temperatures, J. Am. Chem. Soc., 128 (2006) 62826283.

[30] J. Michael Gottfried, K. Christmann, Oxidation of carbon monoxide over $\mathrm{Au}(110)-(1 \times 2)$, Surf. Sci., 566-568, Part 2 (2004) 1112-1117.

[31] B.K. Min, A.R. Alemozafar, D. Pinnaduwage, X. Deng, C.M. Friend, Efficient CO Oxidation at Low Temperature on Au(111), The Journal of Physical Chemistry B, 110 (2006) 19833-19838.

[32] X.Y. Deng, B.K. Min, A. Guloy, C.M. Friend, Enhancement of $\mathrm{O}_{2}$ dissociation on $\mathrm{Au}(111)$ by adsorbed oxygen: Implications for oxidation catalysis, J. Am. Chem. Soc., 127 (2005) 92679270.

[33] V.A. Bondzie, S.C. Parker, C.T. Campbell, Oxygen adsorption on well-defined gold 
particles on $\mathrm{TiO}_{2}$ (110), Journal of Vacuum Science \& Technology A, 17 (1999) 1717-1720.

[34] M.M. Schubert, S. Hackenberg, A.C. van Veen, M. Muhler, V. Plzak, R.J. Behm, CO oxidation over supported gold catalysts-"inert" and "active" support materials and their role for the oxygen supply during reaction, Journal of Catalysis, 197 (2001) 113-122.

[35] J.D. Grunwaldt, A. Baiker, Gold/titania interfaces and their role in carbon monoxide oxidation, Journal of Physical Chemistry B, 103 (1999) 1002-1012.

[36] H. Hakkinen, U. Landman, Gas-phase catalytic oxidation of CO by Au-2(-), J. Am. Chem. Soc., 123 (2001) 9704-9705.

[37] P. Konova, A. Naydenov, C. Venkov, D. Mehandjiev, D. Andreeva, T. Tabakova, Activity and deactivation of $\mathrm{Au} / \mathrm{TiO}_{2}$ catalyst in $\mathrm{CO}$ oxidation, Journal of Molecular Catalysis $\mathrm{A}$, Chemical, 213 (2004) 235-240.

[38] R.A. Ojifinni, J. Gong, N.S. Froemming, D.W. Flaherty, M. Pan, G. Henkelman, C.B. Mullins, Carbonate formation and decomposition on atomic oxygen precovered $\mathrm{Au}(111)$, J. Am. Chem. Soc., 130 (2008) 11250-11251.

[39] J. Kim, E. Samano, B.E. Koel, CO adsorption and reaction on clean and oxygen-covered $\mathrm{Au}(211)$ surfaces, J. Phys. Chem. B, 110 (2006) 17512-17517.

[40] M.L. Kottke, R.G. Greenler, H.G. Tompkins, An infrared spectroscopic study of carbon monoxide adsorbed on polycrystalline gold using the reflection-absorption technique, Surf. Sci., 32 (1972) 231-243.

[41] L. Piccolo, D. Loffreda, F. Aires, C. Deranlot, Y. Jugnet, P. Sautet, J.C. Bertolini, The adsorption of $\mathrm{CO}$ on $\mathrm{Au}(111)$ at elevated pressures studied by STM, RAIRS and DFT calculations, Surf. Sci., 566 (2004) 995-1000.

[42] C. Ruggiero, P. Hollins, Adsorption of carbon monoxide on the gold (332) surface, Journal of the Chemical Society, Faraday Transactions, 92 (1996) 4829-4834. 
[43] N. Saliba, D.H. Parker, B.E. Koel, Adsorption of oxygen on Au(111) by exposure to ozone, Surf. Sci., 410 (1998) 270-282.

[44] P.A. Redhead, Thermal desorption of gases, Vacuum, 12 (1962) 9.

[45] K. Nakamoto, Infrared and Raman spectra of inorganic and coordination compounds, Wiley, New York, 1997.

[46] M. Mihaylov, H. Knozinger, K. Hadjiivanov, B.C. Gates, Characterization of the oxidation states of supported gold species by IR spectroscopy of adsorbed CO, Chemie Ingenieur Technik, 79 (2007) 795-806.

[47] M. Kaltchev, A.W. Thompson, W.T. Tysoe, Reflection-absorption infrared spectroscopy of ethylene on palladium (111) at high pressure, Surf. Sci., 391 (1997) 145-149.

[48] S.D. Senanayake, D. Stacchiola, P. Liu, C.B. Mullins, J. Hrbek, J.A. Rodriguez, Interaction of $\mathrm{CO}$ with $\mathrm{OH}$ on $\mathrm{Au}(111)$ : $\mathrm{HCOO}, \mathrm{CO}_{3}$, and $\mathrm{HOCO}$ as Key Intermediates in the Water-Gas Shift Reaction, The Journal of Physical Chemistry C, 113 (2009) 19536-19544.

[49] P. Dumas, R.G. Tobin, P.L. Richards, Study of adsorption states and interactions of CO on evaporated noble metal surfaces by infrared absorption spectroscopy: I. Silver, Surf. Sci., 171 (1986) 555-578.

[50] P. Dumas, R.G. Tobin, P.L. Richards, Interaction of co molecules with evaporated silver, gold, and copper films: an infrared spectroscopic investigation using a thermal detection technique, Journal of Electron Spectroscopy and Related Phenomena, 39 (1986) 183-189. [51] Y. Jugnet, F. Aires, C. Deranlot, L. Piccolo, J.C. Bertolini, CO chemisorption on Au(110) investigated under elevated pressures by polarized reflection absorption infrared spectroscopy and scanning tunneling microscopy, Surf. Sci., 521 (2002) L639-L644.

[52] K.F. Peters, P. Steadman, H. Isern, J. Alvarez, S. Ferrer, Elevated-pressure chemical reactivity of carbon monoxide over Au(111), Surf. Sci., 467 (2000) 10-22. 
[53] B. Hammer, Y. Morikawa, J.K. Nørskov, CO Chemisorption at Metal Surfaces and

Overlayers, Phys. Rev. Lett., 76 (1996) 2141-2144.

[54] G. Blyholder, Molecular Orbital View of Chemisorbed Carbon Monoxide, The Journal of Physical Chemistry, 68 (1964) 2772-2777.

[55] T.V.W. Janssens, B.S. Clausen, B. Hvolbaek, H. Falsig, C.H. Christensen, T. Bligaard, J.K. Norskov, Insights into the reactivity of supported Au nanoparticles: combining theory and experiments, Top. Catal., 44 (2007) 15-26.

[56] C. Lemire, R. Meyer, S. Shaikhutdinov, H.-J. Freund, Do Quantum Size Effects Control CO Adsorption on Gold Nanoparticles?, Angewandte Chemie International Edition, 43 (2004) 118121.

[57] J. Biener, M.M. Biener, T. Nowitzki, A.V. Hamza, C.M. Friend, V. Zielasek, M. Bäumer, On the Role of Oxygen in Stabilizing Low-Coordinated Au Atoms, ChemPhysChem, 7 (2006) 1906-1908.

[58] R.G. Greenler, Infrared Study of Adsorbed Molecules on Metal Surfaces by Reflection Techniques, The Journal of Chemical Physics, 44 (1966) 310-315.

[59] R.A. Ojifinni, J. Gong, N.S. Froemming, D.W. Flaherty, M. Pan, G. Henkelman, C.B. Mullins, Carbonate Formation and Decomposition on Atomic Oxygen Precovered Au(111), Journal of the American Chemical Society, 130 (2008) 11250-11251.

[60] M.J.P. Hopstaken, J.W. Niemantsverdriet, Structure sensitivity in the CO oxidation on rhodium: Effect of adsorbate coverages on oxidation kinetics on $\mathrm{Rh}(100)$ and $\mathrm{Rh}(111)$, The Journal of Chemical Physics, 113 (2000) 5457-5465.

[61] J. Küppers, A. Plagge, The Langmuir-Hinshelwood Reaction between Oxygen and CO at Ir(111) Surfaces, in: Zeitschrift für Naturforschung A, 1979, pp. 81.

[62] T. Matsushima, H. Asada, Kinetic studies on the CO oxidation on Pd(111) with low energy 
electron diffraction (LEED) and angle-resolved thermal desorption, The Journal of Chemical Physics, 85 (1986) 1658-1668.

[63] J.L. Gland, E.B. Kollin, Carbon monoxide oxidation on the $\operatorname{Pt}(111)$ surface: Temperature programmed reaction of coadsorbed atomic oxygen and carbon monoxide, The Journal of Chemical Physics, 78 (1983) 963-974. 


\section{Figure Captions}

Figure 1:

A. 28 (CO), B. 44 and C. 32 amu TPD profiles of $\mathrm{CO}$ adsorbed at $80 \mathrm{~K}$ on a surface precovered by $0.2 \mathrm{ML}$ of atomic oxygen collected using a heating rate of $3.4 \mathrm{~K} / \mathrm{s}$ as a function of $\mathrm{CO}$ exposure.

Figure 2:

A. $28(\mathrm{CO})$ and B. 44 TPD profiles of $\mathrm{CO}$ adsorbed at $80 \mathrm{~K}$ on a surface precovered by $0.75 \mathrm{ML}$ of atomic oxygen collected using a heating rate of $3.4 \mathrm{~K} / \mathrm{s}$ as a function of $\mathrm{CO}$ exposure.

Figure 3:

A. $28(\mathrm{CO})$, B. 44 and C. $32 \mathrm{amu}$ TPD profiles of $10 \mathrm{~L} \mathrm{CO}$ adsorbed at $80 \mathrm{~K}$ on a surface with various coverages of atomic oxygen collected using a heating rate of $3.4 \mathrm{~K} / \mathrm{s}$ as a function of $\mathrm{CO}$ exposure.

Figure 4:

Plot of the equivalent coverage of carbon dioxide produced versus the coverage of oxygen consumed due to a reaction between atomic oxygen and $\mathrm{CO}$ adsorbed at $80 \mathrm{~K}$ on oxygencovered $\mathrm{Au}(111)$ as a function of oxygen coverage.

Figure 5:

A. RAIRS spectra of $\mathrm{CO}$ on $\mathrm{Au}(111)$ at $87 \mathrm{~K}$ and heated to various temperatures. An inset shows the variation in integrated absorbance with temperature. B. $\mathrm{CO}$ adsorbed on $\mathrm{Au}(111)$ with 0.2 ML of atomic oxygen as a function of oxygen exposure. C. RAIRS spectra of a saturated overlayer of $\mathrm{CO}(\sim 10 \mathrm{~L}$ exposure) on $\mathrm{Au}(111)$ with $0.2 \mathrm{ML}$ of atomic oxygen as a function of annealing temperature. Shown as an inset is the variation in integrated absorbances of the 2141 and $2110 \mathrm{~cm}^{-1}$ peaks as a function of annealing temperature. 


\section{FIGURES}

A

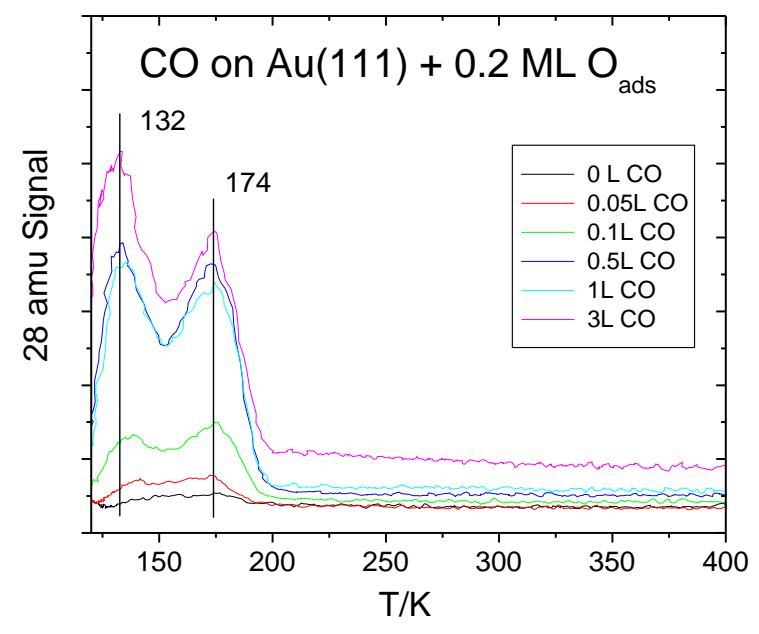

B

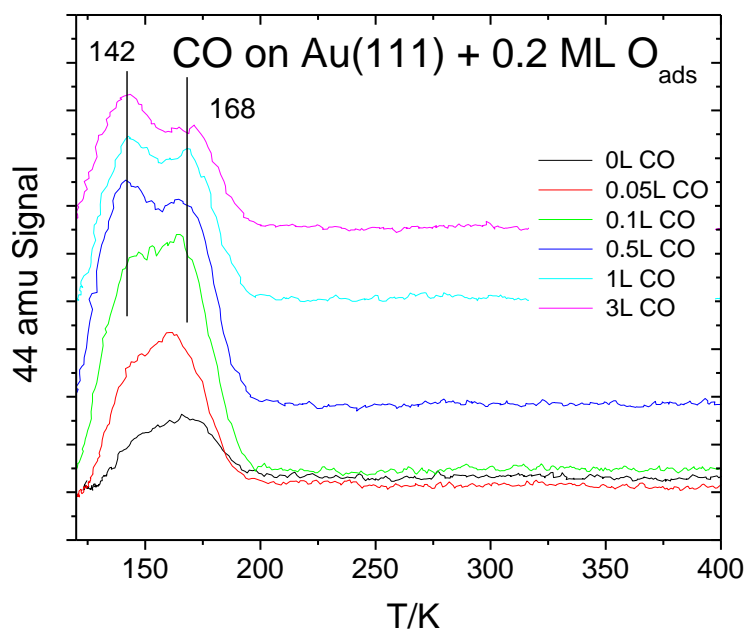

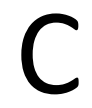

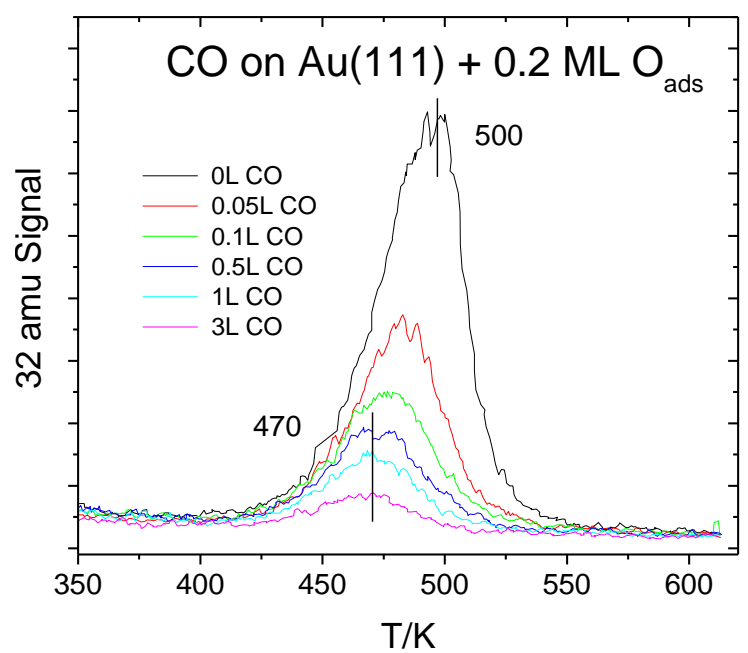

Thuening et al, Fig. 1 
A

B
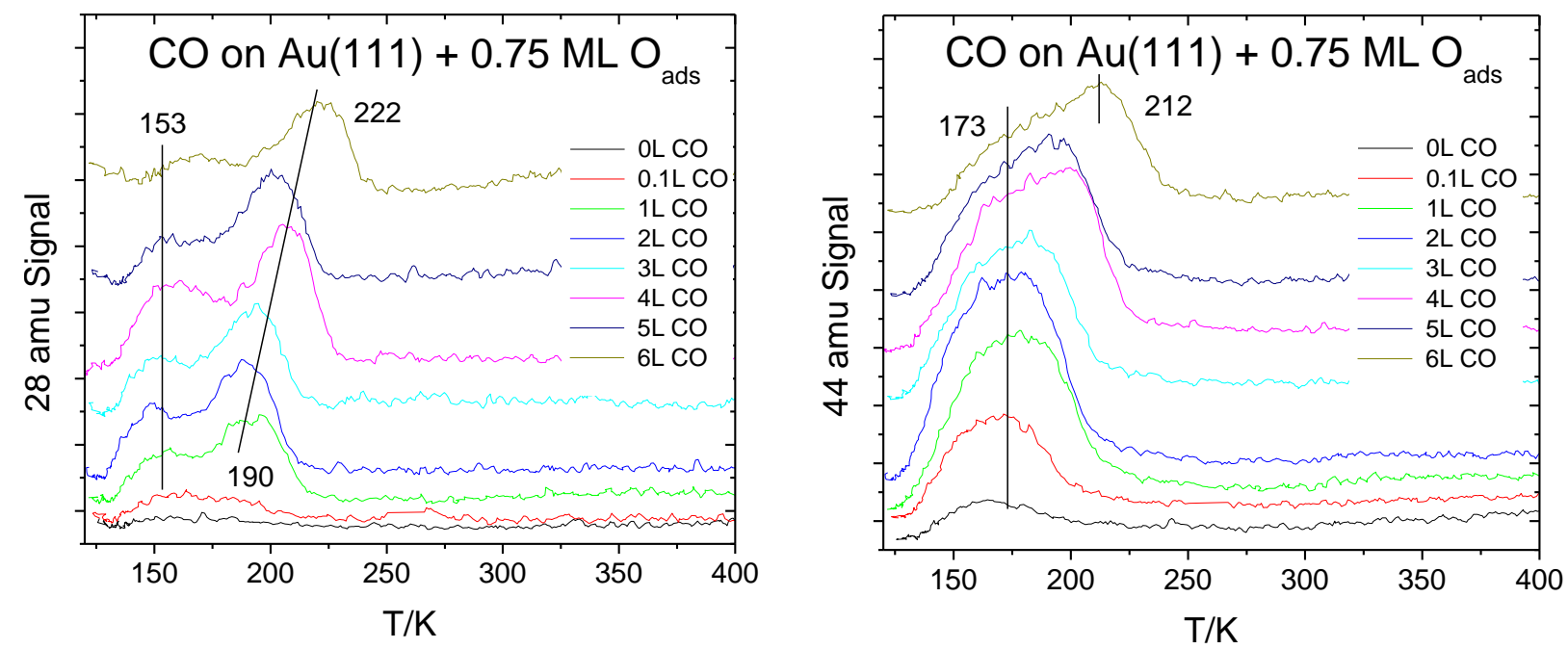

Thuening et al, Fig. 2 
A

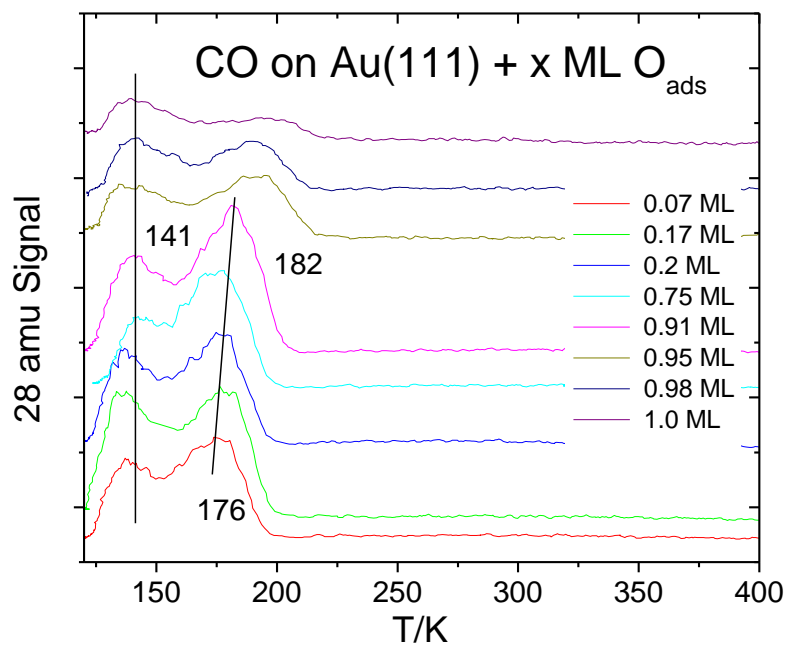

B

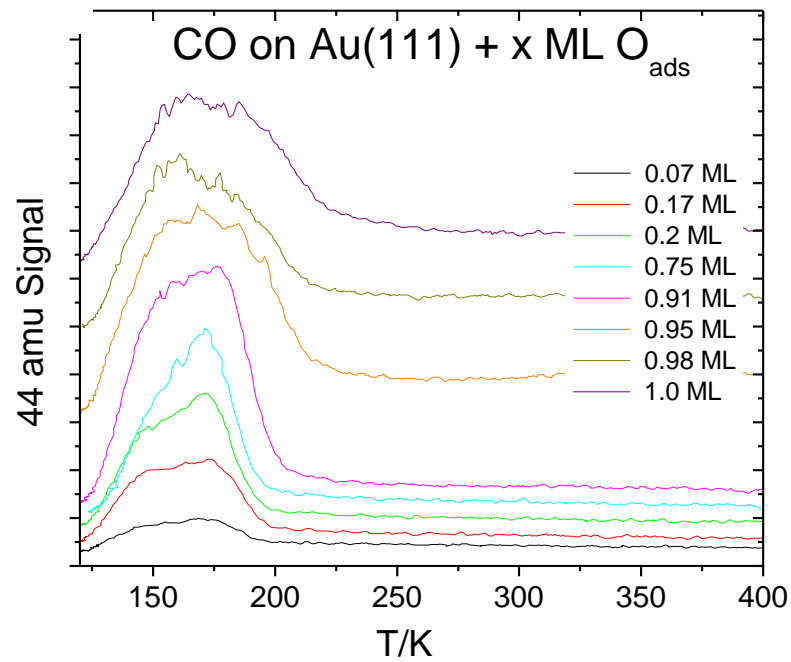

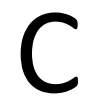

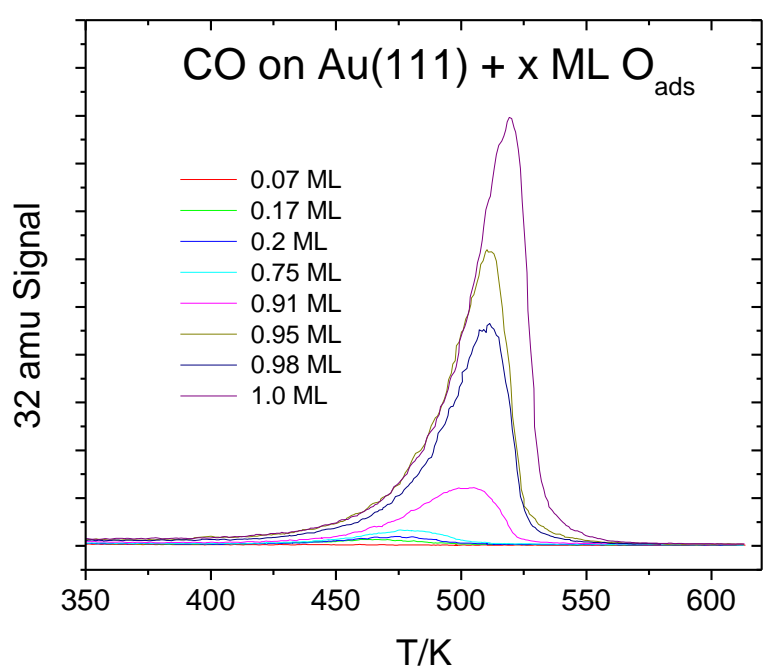

Thuening et al, Fig. 3 


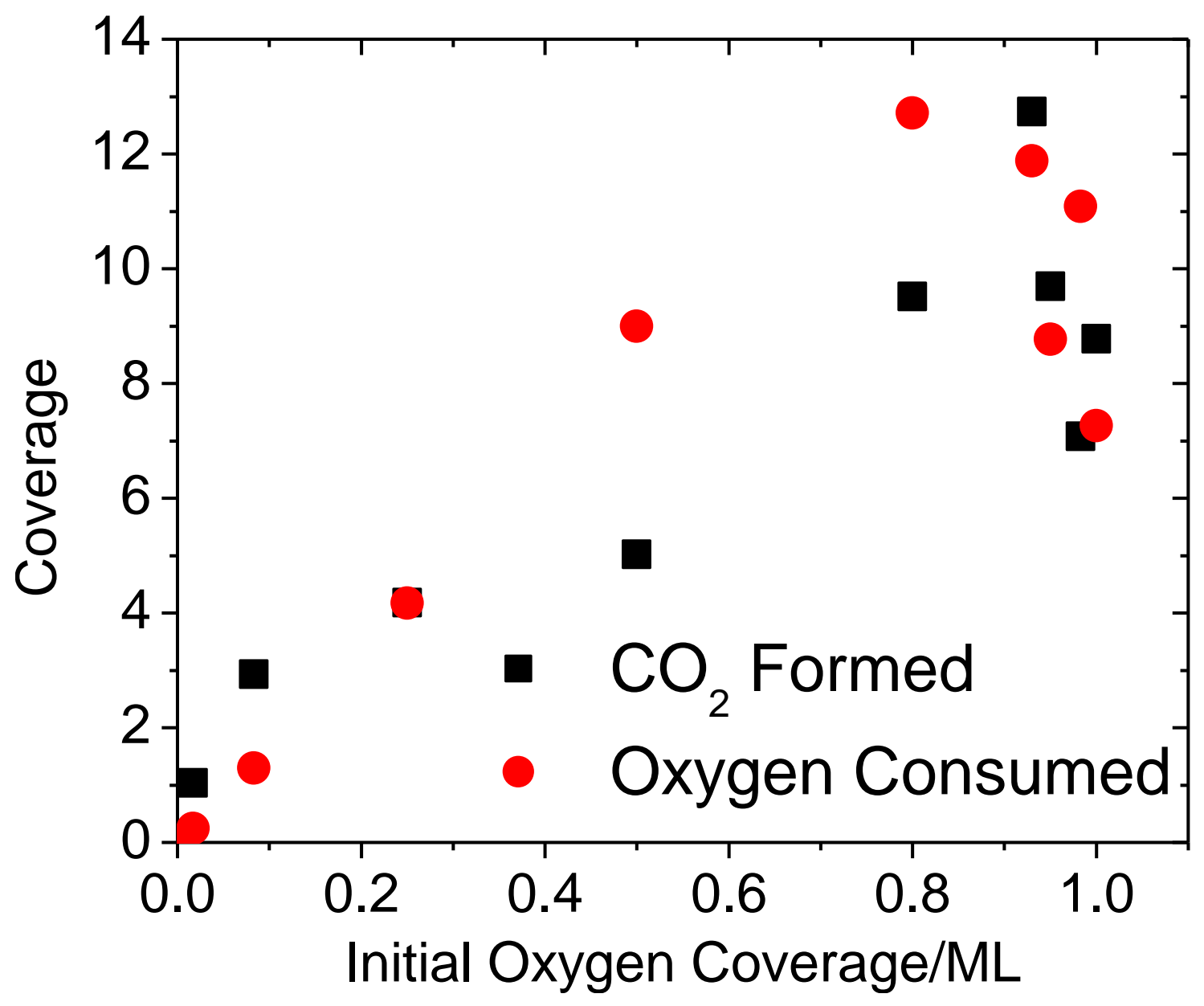

Thuening et al, Fig. 4 
A

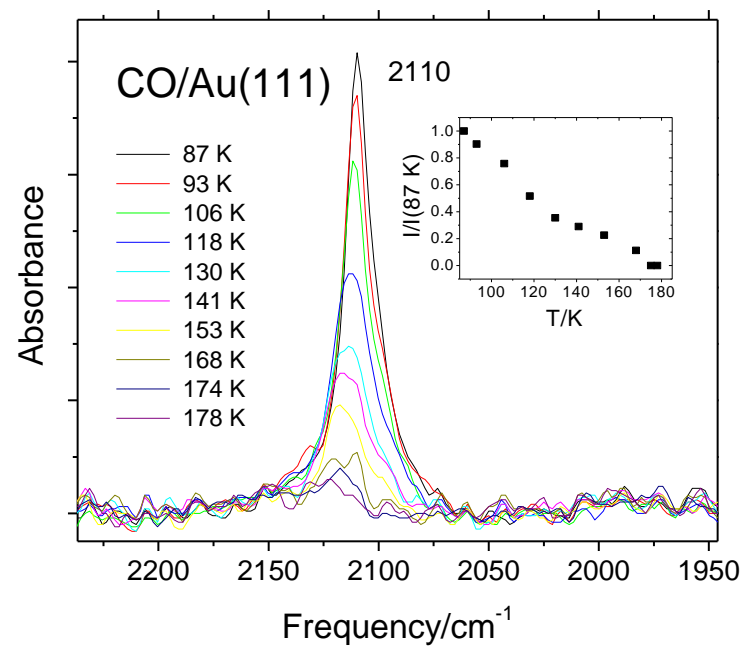

B
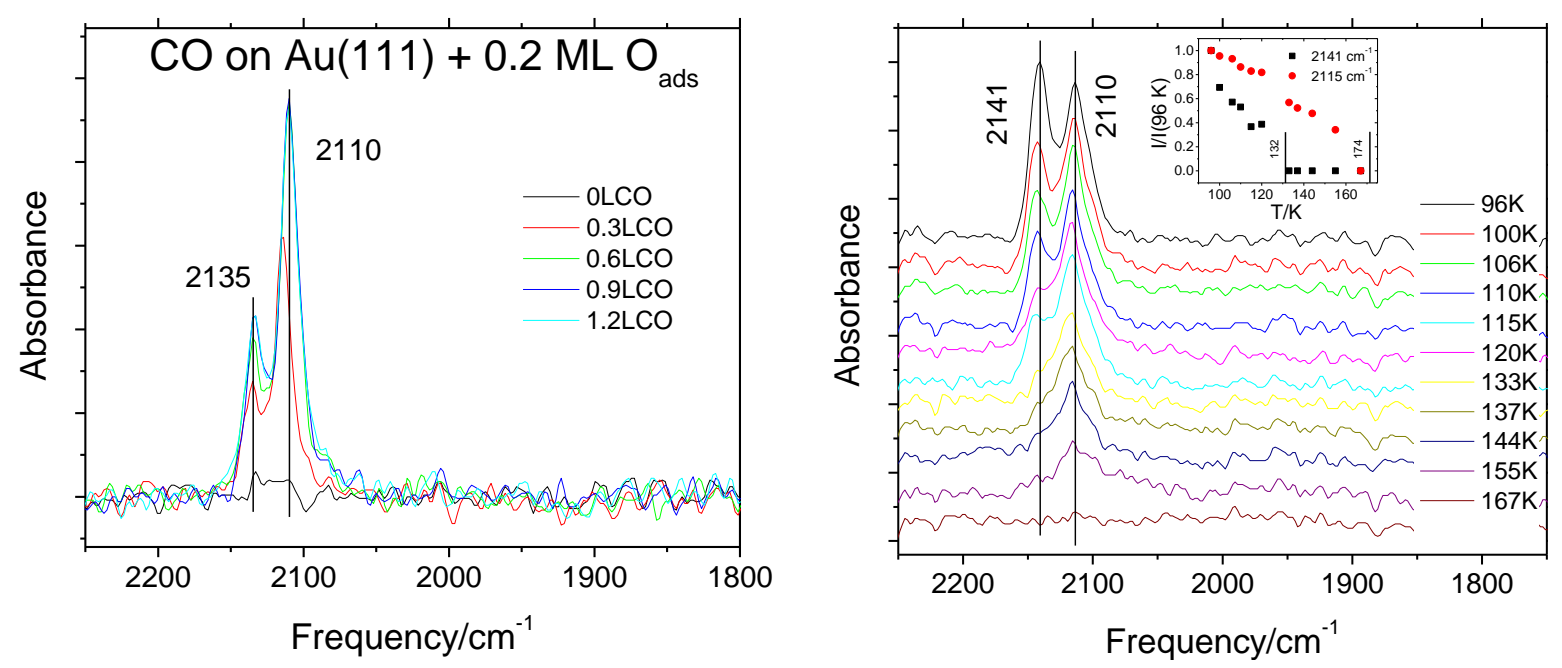

Thuening et al, Fig. 5 
Graphical Abstract

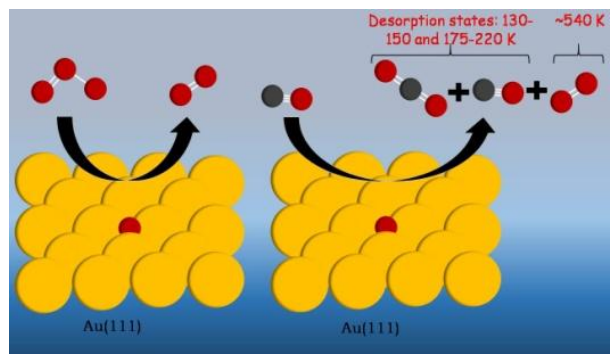

